\title{
A dimensão multilateral da política externa brasileira: perfil da produção bibliográfica
}

\author{
NORMA BREDA DOS SANTOS*
}

\section{Considerações sobre o conceito de multilateralismo}

O multilateralismo praticamente nunca é enfocado tendo-se em mente o que Ruggie denomina de dimensão qualitativa. Esse autor afirma, com razão, que não basta levar em conta a existência de uma coordenação de políticas nacionais entre três ou mais Estados para a configuração de um arranjo verdadeiramente multilateral. Ou seja, a dimensão nominal ou quantitativa de interações interestatais, embora necessária, não é suficiente, pois não enseja a compreensão do que seria um aspecto essencial do multilateralismo, o que explicaria sua eficiência e seu sucesso ou duração ao longo da história.

Além da dimensão nominal, Ruggie entende que o multilateral é definido por sua dimensão qualitativa. Ou seja, segundo o autor, as relações multilaterais referem-se à coordenação entre três ou mais Estados "segundo determinados princípios”, a serem respeitados por todos os Estados que delas participam. Essa definição tem como corolários: 1) a indivisibilidade, no que diz respeito ao tipo de comportamento que deve prevalecer entre os Estados membros de uma coletividade, e 2) a reciprocidade difusa, conceito elaborado por Robert Keohane, relativo ao tipo de expectativa que prevalece no arranjo multilateral - contrariamente às expectativas específicas, típicas de acordos bilaterais, em um acordo multilateral espera-se que os benefícios usufruídos pelos Estados que o compõem se tornarão equivalentes ao longo do tempo. ${ }^{1}$

A segurança coletiva é certamente paradigmática do fenômeno multilateral. Os Estados membros da Liga das Nações e da Organização das Nações Unidas (ONU) partilharam e partilham a obrigação de defenderem-se em conjunto contra toda ameaça de ataque, ainda que essa ameaça apareça concretamente como individual. Exemplo recente de sua aplicação é a reação internacional à invasão iraquiana ao Kuait, em agosto de 1990. O Conselho de Segurança adotou a 
Resolução 678, autorizando os membros da ONU a utilizar “os meios necessários” (leia-se: a força) para assegurar a implementação de resoluções anteriores que exigiam a retirada do Iraque do Kuait e o restabelecimento da paz e da segurança internacionais na área. Com base nessa resolução, a aliança militar liderada pelos Estados Unidos dá início às operações militares contra o Iraque, em 17 de janeiro de $1991 .^{2}$

No caso, a agressão ao Kuait foi considerada, ipso facto, um ataque a todos os membros da ONU. Tendo em mente a definição de Ruggie e os corolários referidos, além da evidência de que a ONU é um arranjo inter-estatal, composto por mais de três membros - nominalmente multilateral -, deve-se destacar que esses membros relacionam-se segundo princípios comuns. A segurança coletiva é o mais relevante entre eles: indivisível, pois há que prevalecer entre todos os membros, que compartilham de uma reciprocidade difusa, que é a expectativa, no caso, de ser defendido por seus pares caso seja agredido.

Chama-se aqui a atenção para tal definição e conceitos por considerá-los importantes à análise que não se preocupa puramente com a descrição dos aspectos institucionais de uma organização internacional ou de um regime internacional, tentando ir além para compreender sua contribuição à governabilidade internacional, sua eficiência, e, por conseguinte, as motivações para a existência de um grau razoável de efetiva adesão dos membros aos princípios que regem tal organização ou regime. ${ }^{3}$

Deve ainda ser notada a existência de uma recente e interessante corrente crítica ao multilateralismo, composta de um espectro acadêmico que vai bem além dos conhecidos “detratores" realistas, englobando, entre outros, um importante grupo de estudiosos do direito internacional público. Para estes, o multilateralismo tornou-se "nossa religião secular”, uma panacéia para todos os males que afligem a humanidade, malgrado o desapontamento gerado pelo mau funcionamento das instituições internacionais, como a ONU. Desafiam a difundida crença de que se melhora o mundo com a expansão da competência e o enforcement power das instituições internacionais. Apontam para o fato de que o "sistema de segurança coletiva, desenhado depois do Holocausto, não impediu disputas intra-estatais nem repetidas atrocidades em massa. No campo econômico, livre comércio/livres forças de mercado (incluindo seus componentes institucionalizados tais como a OMC, o NAFTA e as instituições financeiras internacionais) reforçaram, na realidade, a busca de identidade étnica ao mesmo tempo em que falharam em diminuir a defasagem entre nações ricas e pobres ou a defasagem entre ricos e pobres no interior dessas nações.” 4

Anne-Marie Slaughter, das representantes mais eminentes dessa corrente crítica, lembra ainda que as instituições internacionais (incluindo aí também entidades não-governamentais) agem constantemente de forma unilateral, sob o manto da duvidosa legitimidade que advém do fato de o fazerem em nome de um grupo de 
Estados ou dos interesses de uma coletividade qualquer. O que, de fato, realizam é a defesa da supremacia de um Estado hegemônico ou de um grupo de interesses. Slaughter sugere como exemplo alternativo à tradicional diplomacia inter-estatal a utilização de redes transnacionais de atores domésticos, governamentais e privados, tais como parlamentares e funcionários de bancos centrais, que realizarão mais e de modo mais simples e rápida do que funcionários internacionais o fariam. ${ }^{5}$

Enfim, advogam os críticos que nem sempre, ou muito freqüentemente, os mecanismos multilaterais não são os mais apropriados para a solução de questões que podem ser de interesse internacional, mas não deixam de ter um conteúdo de forte interesse doméstico. Nesse sentido, apontam como exemplo os casos do Camboja e de Ruanda. Em ambos os casos, passado o período de atrocidades, as autoridades nacionais propugnaram a criação de tribunais ou comissões nacionais, aos moldes da Comissão da Verdade, criada na África do Sul para apurar os delitos cometidos sob o apartheid. Foi vencedora, porém, a ONU, com o decisivo apoio da administração norte-americana. ${ }^{6}$

Tendo em mente que essas críticas têm bastante procedência, notadamente quanto ao mito segundo o qual a multiplicação ad infinitum de arranjos multilaterais seria o caminho para a paz e a prosperidade mundiais, algumas observações devem ser feitas. A agenda internacional resulta sempre em grande medida do predomínio estratégico e no plano dos valores da potência hegemônica. Os temas visivelmente predominantes da agenda do mundo globalizado - dos direitos humanos, a democracia, a liberalização comercial, a proteção ambiental, etc. - foram consolidados em razão da hegemonia norte-americana. Porém, não unicamente. Se a geometria das relações internacionais unipolar amplia substancialmente a hegemonia norte-americana no terreno dos valores, fenômeno que percebemos como universalização desses valores, forçoso é constatar que esse universalismo ou ampla existência de valores compartilhados não deixa também de refletir um processo de construção de consenso e de incorporação de diversidades. ${ }^{7}$

\section{A bibliografia brasileira sobre o multilateralismo: os recortes necessários}

O texto a seguir objetiva traçar um perfil, ainda que aproximativo, da produção bibliográfica brasileira voltada para a interação multilateral do Brasil. Tratando-se de tarefa tão ampla, alguns critérios de inclusão/exclusão foram estabelecidos. Primeiramente, optou-se por incluir somente artigos de periódicos. Exclui-se, portanto, livros, dissertações de mestrado e teses de doutorado. Excluise, ainda, publicações que contêm notas de caráter sobretudo informativo, como Panorama da Conjuntura Internacional e Carta Internacional, e a produção acadêmica veiculada eletronicamente por RelNet (Site Brasileiro de Referência em Relações Internacionais). ${ }^{8}$

Assim, o levantamento realizado teve como objeto principal os periódicos brasileiros especializados em relações internacionais que são, em geral, considerados 
pelos estudiosos como os mais importantes: Contexto Internacional, Política e Estratégia, Política Externa e Revista Brasileira de Política Internacional. Contexto internacional é publicada semestralmente pelo Instituto de Relações Internacionais (IRI-PUC), Rio de Janeiro, desde 1985. Política e Estratégia teve vida curta, porém bastante profícua: foi publicada de 1983 a 1991, pelo Centro de Estudos Estratégicos da Sociedade de Cultura Convívio (São Paulo). Política Externa é publicada desde 1992 pelo NUPRI (Núcleo de Pesquisa em Relações Internacionais e Política Comparada) da USP. A Revista Brasileira de Política Internacional ${ }^{9}$ é publicada há mais de quatro décadas pelo IBRI (Instituto Brasileiro de Relações Internacionais): de 1958 até 1993 o IBRI tinha sede no Rio de Janeiro; desde então sua sede está em Brasília. ${ }^{10}$

Com tais parâmetros ou "filtros", o levantamento realizado permitiu de todo modo observar a existência de uma produção vastíssima sobre os mais diversos aspectos da atuação multilateral do Brasil. A publicação desses estudos, em quantidade e em qualidade, reflete em geral a predominância que certos temas adquirem, em momentos diversos, na agenda internacional e para a política externa brasileira. Temas como o direito do mar, o colonialismo, a segurança e o desarmamento, o Tratado da Antártida, o Tratado de Itaipu, as negociações comerciais e multilateralismo econômico de forma geral, etc, foram discutidos em muitos trabalhos. Sem dúvida alguma, porém, o desenvolvimento, elemento paradigmático da política externa brasileira desde 1930, foi o tema mais recorrente. Constata-se também uma expressiva expansão da temática multilateral, enriquecida notadamente nos últimos anos com a atenção que ganharam a proteção internacional dos direitos humanos, o meio ambiente, o terrorismo e o narcotráfico. ${ }^{11}$

Feitas todas estas observações, escolheu-se, finalmente, estudar os menos numerosos trabalhos que se propõem a realizar um balanço da atuação multilateral brasileira. O conjunto desses trabalhos permite uma análise de períodos mais longos, bem como detectar o peso relativo de determinadas preocupações ou temas ao longo do tempo.

Enfim, cabe, por último, esclarecer a estratégia utilizada para organizar a bibliografia encontrada. Primeiramente, trata-se dos estudos que enfocam a dimensão multilateral da política externa brasileira no tempo médio, ou seja, aspectos conjunturais, que têm, justamente por isso, uma relevância especial. Em seguida, são comentados os trabalhos sobre períodos curtos, que os historiadores têm denominado mais recentemente de história do tempo presente. ${ }^{12}$

\section{Os estudos sobre o tempo médio: as conjunturas}

Duas referências aparecem como pontos de passagem obrigatórios aos que queiram estudar o desempenho multilateral do Brasil, seja qual for o assunto de seu interesse específico. Com efeito, os estudos de Antônio Augusto Cançado 
Trindade e de Clodoaldo Bueno, o primeiro jurista e o segundo historiador, oferecem amplos e bem documentados panoramas da ação multilateral do Brasil, sendo, pelos próprios propósitos estabelecidos pelos autores, de natureza sintética. Estudos com conteúdo mais analítico do que descritivo - o que pressupõe, portanto, que o leitor tenha alguma familiaridade com a história da política externa brasileira -, são os textos de Celso Lafer, de Paulo Roberto de Almeida e de Alexandra de Mello e Silva.

O artigo de Cançado Trindade ${ }^{13}$ dedica-se a examinar "amostras de posições, atitudes e pronunciamentos básicos da delegação do Brasil em alguns dos organismos políticos internacionais em que se faz representar, selecionando igualmente algumas áreas específicas de atuação” ${ }^{14}$, englobando o período 1945final dos anos 70. Seu levantamento dá ênfase às posições brasileiras consideradas mais significativas em órgãos e conferências da ONU: Assembléia Geral, Conselho de Segurança, Unctad (Conferência das Nações Unidas para o Comércio e Desenvolvimento) e conferências sobre direito do mar, sobre o meio ambiente, sobre o direito dos tratados e sobre população. O trabalho utiliza principalmente documentos publicados pelo Itamaraty (relatórios anuais apresentados pelo Itamaraty ao presidente, relatórios das delegações de diversas reuniões, etc.), documentos da ONU e uma ampla bibliografia sobre os temas tratados.

Um dos cinco subtítulos do artigo de Cançado Trindade (excluindo-se a introdução e a conclusão) é inteiramente dedicado à Conferência de São Francisco, que elaborou a Carta da ONU, e um longo subtítulo é dedicado à Unctad. Com relação à Conferência de São Francisco, o destaque aqui se justifica pelo fato de a reunião não ter merecido, em geral, mais do que poucas linhas dos estudiosos. Cançado Trindade lembra, por exemplo, que o Brasil, desde então, defendia a flexibilidade da Carta, ou seja, que seus dispositivos pudessem e devessem ser objeto de revisão contínua, para que se adaptassem às novas realidades.

Cançado Trindade, demonstra muito claramente o quanto na década de 80, quando seu artigo é publicado, ainda sobrevivia a crença, marcante sobretudo nas décadas de 60 e 70, de que a Unctad era o caminho privilegiado para alcançarse um comércio internacional mais justo. O Gatt, por sua vez, e provavelmente pelo mesmo motivo, praticamente não recebe atenção do autor, sendo mencionado somente obliquamente. ${ }^{15}$ É verdade que apesar dos hoje visíveis problemas de ineficiência da Unctad, a instituição foi importante para que se introduzisse no Gatt instrumentos legais que refletiam a ideologia desenvolvimentista.

Em sua conclusão, Cançado Trindade lembra justamente que o Brasil passou a expressar maior apoio aos foros multilaterais a partir de 1968, II Unctad, “como meio de neutralizar ou reduzir o considerável poder de coerção das superpotências e grandes poderes nas relações internacionais”. ${ }^{16}$

O estudo de Bueno ${ }^{17}$ é mais recente e retraça, através de eixos temáticos e recortes temporais, o espectro da atuação da diplomacia brasileira no sistema da 
ONU, de 1945 até 1988. Utiliza-se, sobretudo, de documentação diplomática do Arquivo Histórico do Itamaraty e dos relatórios anuais apresentados pelo Ministério ao presidente da República. Nota-se a preocupação do autor em inserir os temas abordados em uma perspectiva mais geral da política externa brasileira, possibilitando sua melhor contextualização histórica.

Bueno assinala que "a política multilateral brasileira não apresenta muitas e significativas viragens", enfatizando, pois, o aspecto da continuidade, que resultaria do alto grau de profissionalização do Itamaraty. "Por tal razão é que mudanças significativas no plano interno nem sempre correspondem a mudanças no mesmo nível de intensidade, na face externa". ${ }^{18}$

Segundo Bueno, logo tornou-se evidente para a diplomacia brasileira a inexistência de um trade off compensatório entre custo de participação na ONU e a transferência de recursos - recursos financeiros e tecnologia. A participação brasileira na ONU cedo foi percebida pelo Brasil como um exercício de "prestígio multilateral caro", que "[proporciona] ganhos políticos, mas não econômicos”. Segundo Bueno, apesar de cedo ficar clara a inexistência de uma relação compensatória entre o custo de participação na ONU e a transferência de recursos - recursos financeiros e tecnologia - a fim de garantir o desenvolvimento do país, a diplomacia brasileira teve na organização internacional uma participação constante e cooperativa, assumindo posições nacionalistas, que manifestavam sua preocupação com o tema do desenvolvimento; posições estas que durante muito tempo traduziramse na defesa da agro-exportação.

Ainda assim, a diplomacia brasileira tem tido uma participação constante e cooperativa na ONU, assumindo posições nacionalistas e que manifestam sua preocupação com o tema do desenvolvimento. A busca do desenvolvimento é, assim, o tema que permeia todo o estudo de Bueno. É a dimensão que dá conteúdo à continuidade da política externa brasileira, presente em todos os temas discutidos no trabalho. E são muitos: a participação brasileira no Conselho de Segurança, na Assembléia Geral, no Ecosoc (Conselho Econômico e Social, órgão muito importante nas duas primeiras décadas de funcionamento da ONU), no Gatt e na Unctad; nos debates sobre o desarmamento, o colonialismo, fundos marinhos e mar territorial, meio ambiente, população e a questão da dívida externa.

O estudo de Paulo Roberto de Almeida ${ }^{19}$ enfoca a construção da ordem internacional desde o início do século XIX - que recebe uma atenção muito particular e dá especificidade ao texto -, dando ênfase a dimensão econômica no histórico traçado. Os pontos de passagem destacados são o Congresso de Viena, as conferências técnicas realizadas na segunda metade do século XIX, a Liga das Nações e o sistema onusiano. O autor lembra que "o Brasil foi um dos países ditos 'periféricos' que mais participaram da construção da ordem internacional desde meados do século XIX até os dias atuais”. ${ }^{20}$

Assim, as comumente muito pouco focalizadas conseqüências do Congresso de Viena (1815) para o Brasil - provavelmente por não ser independente à época 
- são indicadas por Almeida em seu trabalho. Naquele momento, o Brasil, de colônia, passa à condição de Reino. Além disso, duas questões tratadas em Viena têm repercussões para o Brasil: a livre navegação de rios internacionais e a restrição ao tráfico de escravos.

O sucesso do Concerto Europeu garantiu a paz européia por praticamente um século e serviu à expansão do capitalismo industrial. Já no começo do século XIX aparecem as primeiras instituições internacionais, mas estas se estabelecerão, sobretudo, a partir da segunda metade do século. Com efeito, a intensidade do intercâmbio comercial, tecnológico e financeiro leva à realização das primeiras conferências e instituições internacionais de cooperação técnica, através das quais os governos nacionais buscam desmantelar entraves ao desenvolvimento de suas economias. Surgem, entre outras, a União Telegráfica Internacional (1865), a União Postal Internacional (1874), a Associação Internacional do Congresso de Ferrovias (1884), a União Radio Telegráfica Universal (1906), às quais o Brasil adere.

Lembra o autor que, dessas instituições, as organizações internacionais políticas mais importantes do século XX, a Liga das Nações e a ONU, herdam o universalismo e o aprendizado na esfera da institucionalização da cooperação técnica, ou seja, as estruturas formais para que a cooperação se realizasse, através, por exemplo, da criação de secretariados internacionais.

A criação da Liga das Nações traz como novidade e ambição a substituição dos acordos políticos bilaterais e secretos por uma diplomacia universal e aberta, ou pública. Este ideal wilsoniano não vingou, o que está demonstrado pelos historiadores, tendo, inclusive, o Brasil protagonizado a primeira grande crise surgida da contradição entre a velha e a nova diplomacia. Afora essa questão, nada de substancial e de interesse brasileiro se passaria no âmbito do multilateralismo econômico promovido pela Liga.

Sobre o impacto para o Brasil do perfil que ganha o multilateralismo pós1945, Almeida menciona, no âmbito comercial, o tratamento especial e mais favorável para os países em desenvolvimento, para cuja aceitação a diplomacia brasileira exerceu papel ativo, nos anos 1960-1980.

Lafer $^{21}$ utiliza uma perspectiva de sistema em seu texto, buscando relacionar os níveis global, regional e nacional a fim compreender “o relacionamento político nacional e a política exterior [brasileira] até o fim do governo Castelo Branco". ${ }^{22}$ Começando sua análise no Império, entende que nesse período a política externa busca atuar de forma independente em nível global, não aceitando passivamente o domínio britânico. No subsistema regional, entendido aqui como América do Sul, o Império pratica a balança de poder, evitando principalmente o predomínio da Argentina. ${ }^{23}$

O momento mais importante das primeiras décadas da República viria com a indicação do Barão do Rio Branco para chefiar o Itamaraty (1912). Perspicaz e consciente do inescapável e crescente poder norte-americano, Rio Branco busca 
relações especiais com a potência emergente e, ao invés de opor-se à Doutrina Monroe, vai reinterpretá-la e “multilateralizá-la”. Esse importante deslocamento conceitual coloca a defesa do continente americano nas mãos de todos os países do continente, o que, até então, era unicamente fonte para a ingerência unilateral norte-americana. ${ }^{24}$

Segundo Lafer, a “americanização” da política externa brasileira seguirá até o fim da Segunda Guerra Mundial, o que torna compreensível que, naquelas décadas, a participação do Brasil na política européia tenha, sobretudo, um caráter ornamental. Embora o autor não a mencione explicitamente, pode-se provavelmente pensar aqui no que tem sido interpretado como participação ornamental brasileira na Liga das Nações. ${ }^{25}$ Em 1945, o Brasil teria aceito, no âmbito interamericano e global, a tarefa de defender os interesses americanos. De fato, percebe-se que a atuação brasileira na ONU e na OEA está impregnada da visão norte-americana sobre o conflito Leste-Oeste, o que começa a ser questionado por volta dos anos 1950. Surge, então, a Operação Pan-americana, de iniciativa brasileira que propõe novas bases para o relacionamento multilateral no continente, em que a batalha pelo desenvolvimento ficava em primeira linha.

Chega-se aos anos 1960 com a convicção que o campo adequado de atuação internacional do Brasil deveria ser universal. Entre a OEA e a ONU, ficase com a última: "O País deliberou utilizar-se das vantagens da bipolaridade para aumentar o seu poder de barganha e desta maneira reter a possibilidade de autodeterminar-se.”26 Estão aí as bases da Política Externa Independente, política interrompida pelos militares em 1964.

Por seu turno, o artigo de Mello e Silva chama a atenção para o impacto das idéias na formulação da política externa brasileira e, nesse sentido, para a importância de se "reconstruir as principais crenças e idéias presentes em nosso discurso diplomático" 27 , identificando as concepções sobre a natureza e a estrutura do sistema internacional, sobre o modo de inserção que teria o País no sistema internacional e sobre a identidade nacional e sua manifestação externa.

A autora caracteriza, inicialmente, a trajetória epistemológica dos estudos sobre política exterior brasileira: remete-se, primeiramente, ao momento do aparecimento desses estudos, marcado pela prevalência da história diplomática, escrita em geral por estudiosos ligados à burocracia governamental; somente em torno dos anos 60/70 a política externa brasileira passaria a ser crescentemente objeto da pesquisa acadêmica. "[E]ssa institucionalização tardia da pesquisa universitária teve repercussões não apenas sobre as temáticas e enfoques teóricos dominantes nessa área, como também no fato de que o debate acadêmico tendeu a privilegiar dimensões normativas e prescritivas" ${ }^{28}$, sem dar a devida atenção à dimensão cognitiva da formulação da política externa brasileira contemporânea. Com essa constatação, Mello e Silva propõe-se a identificar a origem das idéias e sua influência. 
Lembra Mello e Silva que as insuficiências do realismo fizeram com que aparecessem, no campo das relações, vertentes que procuravam enxergar mais do que o Estado como ator (único e racional), tentando compreender o que a autora metaforicamente denomina de "caixa preta”, ou seja, a compreensão das variáveis que, dentro e fora do Estado, informam a concepção de sua política externa. "Tal análise - buscada pela autora em seu estudo - deve se pautar, primeiramente, pela reconstrução das crenças presentes no discurso diplomático para, a seguir, desvendar os mecanismos causais que explicam as influências daquelas crenças sobre a formulação de políticas”. ${ }^{29}$

O recorte empírico proposto é a atuação do Brasil na Liga das Nações e na ONU, particularmente quando a diplomacia brasileira investe em tentativas de participar do núcleo decisório dessas organizações internacionais. Realismo, pacifismo, não-intervencionismo, respeito ao Direito Internacional, aspiração a desempenhar um papel internacional protagônico são certamente idéias e crenças duradouras que se destacam e que explicam o comportamento diplomático brasileiro. A forte institucionalização do Itamaraty engendraria a reprodução de uma tradição diplomática que reproduz aquelas idéias e crenças, e mais generalizadamente, a reprodução de uma maneira de apreender o mundo, assimilada, assim, por gerações e gerações de diplomatas.

\section{Estudos sobre o tempo curto: a história imediata}

Os trabalhos que seguem tratam da política multilateral do Brasil das últimas três décadas: Wayne Selcher, Mônica Hirst e Letícia Pinheiro, Alessandra Mello e Silva, Shiguenoli Myiamoto, Amado Luiz Cervo e Raúl Bernal-Meza. Ainda que expressem avaliações às vezes bastante diferenciadas, têm, quase todos, como traço comum a ênfase ao multilateralismo econômico, atribuindo significativo espaço às questões envolvendo as estratégias para o Mercosul, a Alca e a OMC.

O livro de autoria de Selcher ${ }^{30}$ é mais um ponto de passagem obrigatório pelo conteúdo analítico e instrumentos metodológicos utilizados pelo autor. Originalmente tese de doutorado, Brazil's Multilateral Relations: between First and Third Worlds, como o título indica, parte do pressuposto de que categorias comumente utilizadas para indicar a inserção do Brasil no sistema internacional, sobretudo a década de 70 - América Latina, Terceiro Mundo, país não-alinhado, relações Leste-Oeste ou Norte-Sul - são pouco úteis para compreender os reais interesses e posições assumidas pelo País, que se percebe como potência média e que busca no período maior proeminência no cenário internacional. O governo brasileiro não é primeiro e tampouco quer ser considerado terceiro mundo, e, segundo Selcher tem uma visão marcadamente instrumental dos contatos multilaterais, vendo-os como uma via para, de um lado, melhorar sua posição na hierarquia internacional e exercer maior peso nos processos decisórios, e, de outro, para 
fazer avançar seus relacionamentos bilaterais pela cooperação tática com determinados países ou grupo de países. Estudando o padrão do voto do Brasil na ONU, o autor confronta o nível discursivo oficial da política externa brasileira com os seus reais limites práticos, demonstrando que resulta daí uma política “com grande visibilidade em certos temas multilaterais técnicos e econômicos, como direito do mar, comércio, transporte marítimo, e de exposição mínima em questões mais controversas, como os da África austral e do Oriente Médio". ${ }^{31}$

Finalmente, situando sua análise no período que vai do "milagre brasileiro" (governo Médici), passando pela crise internacional do petróleo até as readaptações do II PND-Plano Nacional de Desenvolvimento (governo Geisel), ou seja, um período marcado por crescentes problemas no modelo de desenvolvimento adotado pelo regime militar, Wayne Selcher vê mais do que a luz no final do túnel, persuadido de que o governo brasileiro e sua diplomacia seriam, de fato, capazes de alçar o País a uma posição de maior proeminência no cenário mundial. ${ }^{32}$

Hirst e Pinheiro ${ }^{33}$ estudam as mudanças e continuidades dos governos Collor de Mello e Itamar Franco (1990-1994). Segundo as autoras, o governo Collor dá início a um processo que se queria fundamentalmente oposto ao projeto de inserção construído a partir de 1974, caracterizado pela opção autonomista, independente e bastante ativa internacionalmente. O processo iniciado por Collor mostrou-se, afinal, sem grande fôlego. ${ }^{34}$ O que se detecta é que, em 1993, fatores internos e externos levam a uma alteração nas estratégias de inserção internacional do Brasil, o que não modifica substancialmente as opções de inserção propriamente dita.

Esse é o argumento central das autoras, que têm, portanto, uma interpretação que se diferencia das interpretações correntes, que colocam praticamente em exclusivo destaque as novidades introduzidas pelo governo Collor. Com efeito, afirmam que "as mudanças propostas para a política internacional brasileira não alteraram seus aspectos essenciais, i.e., sua estreita vinculação com o modelo econômico do país. Da mesma forma que a política de corte autonomista continha um sentido fortemente instrumental para a estratégia desenvolvimentista brasileira, pretendia-se que o novo padrão de política externa fosse um apoio para os desafios internacionais a serem enfrentados pelo país a partir de seu processo de reformas econômicas internas.”35

Assim, o governo Collor teria, de fato, começado sob o signo do dinamismo e com uma agenda que visava renovar o perfil internacional do país. As metas anunciadas continham resumidamente três prioridades: atualização da política externa segundo a nova agenda internacional, melhorar as relações com os Estados Unidos e tirar do Brasil o rótulo de terceiro-mundo. Os resultados que se destacam dão-se, sobretudo, na arena multilateral: o papel de liderança do Brasil na Eco-92, a assinatura do Tratado de Assunção para a formação do Mercosul, a criação da Agência Brasileiro-Argentina de Contabilidade e Controle de Materiais Nucleares 
(ABACC), a assinatura do Acordo Nuclear Quadripartite de Salvaguardas com a Agência Internacional de Energia Atômica (AIEA) e a iniciativa de revisão do Tratado de Tlatelolco.

O fim abrupto do governo Collor compromete os objetivos traçados para a agenda internacional. O neoliberalismo perde espaço para o neodesenvolvimentismo. Itamar Franco, estando tanto na frente interna quanto na externa bastante fragilizado, dá continuidade aos itens em andamento, ao mesmo tempo em que retoma o discurso desenvolvimentista para o país. Novamente é na arena multilateral que as opções são mais visíveis. Na ONU a diplomacia brasileira torna-se mais ativa, tentando viabilizar a adoção da proposta brasileira de uma Agenda para o Desenvolvimento e defender posições não-intervencionistas nas discussões sobre os direitos humanos, o meio-ambiente e o terrorismo. Na OEA defende o fortalecimento da democracia, mas também é contra o intervencionismo. Nas discussões da Rodada Uruguai segue as alterações traçadas no governo Collor, flexibilizando a oposição à inclusão dos novos temas, com vistas à liberalização agrícola, em particular. Enfim, imprimese às negociações do Mercosul um sentido de prioridade.

Partindo da constatação de que a diplomacia brasileira demonstra nos anos 90 "uma razoável concentração de atenções e recursos sobre a reforma e ampliação do Conselho de Segurança”, visando a obtenção de um assento permanente, o texto de Mello e Silva ${ }^{36}$ busca refletir sobre a questão a partir dos pronunciamentos diplomáticos brasileiros, reveladores da percepção da diplomacia brasileira sobre a conjuntura internacional e o que resulta como orientação para buscar a inserção internacional adequada para o Brasil.

Nesse sentido, a autora observa que dois momentos distintos aparecem no pós-Guerra Fria. O primeiro pós-Guerra Fria iria da queda do Muro de Berlim, em 1989, à Guerra do Golfo em 1990/91. Nele a diplomacia brasileira mostra-se otimista e satisfeita com a ordem internacional, pois considera que predominam internacionalmente forças de integração. Estas forças engendram a constituição de uma comunidade internacional, pois seus membros partilham dos mesmos valores básicos (as regras do mercado e da democracia liberal). O papel da ONU é revalorizado. O Conselho de Segurança, não mais paralisado pelos vetos constantes de Estados Unidos e União Soviética, passa a mostrar-se mais eficaz, a exemplo de sua atuação durante a Guerra do Golfo.

O segundo pós-Guerra Fria começaria com a desintegração da União Soviética e da antiga Iugoslávia. Ganham força os conflitos intra-estatais, de natureza étnica, religiosa, etc. Os problemas que surgem nas diversas operações de paz estabelecidas no período (na Bósnia e na Somália), bem como a atuação do Conselho de Segurança durante a crise no Haiti, fazem do órgão o alvo de muitas críticas e sua reforma e ampliação é rediscutida. O otimismo e a crença no bom funcionamento do sistema internacional dá lugar, portanto, a uma orientação realista, que entende que as instâncias internacionais devem adequar-se à existência de novos pólos de 
poder. O sistema internacional redefine então suas regras e o Brasil, por reunir uma série de atributos que o qualificam a uma maior participação na elaboração dos novos mecanismos regulatórios das relações internacionais, coloca-se como candidato a um assento permanente no Conselho de Segurança.

Mello e Silva aponta em sua conclusão as ambigüidades que encerra a candidatura ao assento permanente no Conselho de Segurança, reveladora "de uma tradição diplomática que oscila entre a defesa da justiça e da igualdade e o anseio de participação em 'diretórios’ que refletem, de fato, a distribuição desigual de poder no sistema internacional”.

Shiguenoli Myiamoto ${ }^{37}$ busca responder à questão que está mais ou menos implícita em todos os trabalhos aqui tratados: "Por que o Brasil sempre deu importância às instâncias multilaterais e às reuniões internacionais?”38 Em uma palavra, porque não as pode ignorar. Por sua característica de país médio, que não optou pela utilização da força para resolver os conflitos em que se envolve, o Brasil dos anos 90 defende seus interesses privilegiadamente pela via institucional, seja pela participação em organizações internacionais, seja pela sua inclusão em regimes internacionais.

Assim, Miyamoto enfoca as negociações multilaterais na década de anos 90, buscando sua especificidade em relação a momentos anteriores. Durante o período militar (1964-1985), comparativamente, embora não se ausentasse dos foros internacionais, o binômio segurança/ desenvolvimento fez com que a política externa brasileira fosse notoriamente mais defensiva. Com a redemocratização do país, a desintegração da União Soviética, o fim da Guerra Fria, etc., o Brasil multiplicará mais e mais sua presença multilateral. Para o autor, exemplos dessa opção são a Eco-92 e a candidatura do Brasil a um assento permanente no Conselho da ONU: ao desfazer uma imagem de país negligente quanto às questões ambientais, a diplomacia brasileira ganharia em desenvoltura para reivindicar posições de maior relevo no cenário internacional.

Outro exemplo das opções brasileiras nos anos 90 é o aprofundamento dos processos de cooperação regional e inter-regional. No primeiro caso, o Mercosul aparece em destaque; no segundo a cooperação Mercosul-União Européia. O autor entende que na OMC a atuação brasileira tem sido ainda defensiva, a não ser na crítica tenaz que faz ao protecionismo europeu e norte-americano à agricultura.

Shiguenoli conclui seu estudo laconicamente afirmando que "como a capacidade que o [Brasil] tem de alterar as regras de funcionamento do sistema internacional é extremamente limitada, resta apenas utilizar os expedientes de que tem lançado mão ao longo dos últimos anos (...) clamando pela necessidade de cooperação cada vez maior, já que sendo todos interdependentes, [os países desenvolvidos] seriam afetados igualmente pelas crises dos países menos desenvolvidos. Pelo que se tem observado nas reuniões entre os dois lados, esses argumentos, contudo, parecem não ter surtido o efeito desejado”. ${ }^{39}$ 
Os dois últimos artigos, de Amado Luiz Cervo e de Raúl Bernal-Meza, foram publicados recentemente e analisam a política externa brasileira dos anos 90 até o presente de maneira bastante crítica, embora suas interpretações sejam distintas em vários aspectos.

$\mathrm{O}$ artigo de Cervo ${ }^{40}$ dá maior ênfase ao governo de Fernando Henrique Cardoso, sublinhando sua falta de estratégia de inserção internacional para o Brasil. Segundo o autor, os dois mandatos de Cardoso desviaram a política externa de sua estratégia mais contínua e relevante - a busca de insumos para a realização do desenvolvimento do país -, nada colocando em seu lugar, afora a abertura de mercados, o que teria provocado um retrocesso.

Cervo identifica três orientações na política externa brasileira dos anos 90 . A década assiste a substituição do "Estado desenvolvimentista" - agente do desenvolvimento nacional, buscado através da superação da dependência econômica do país e da via autônoma para alcançar sua segurança.-- pela mal sucedida mistura de "Estado normal”/“Estado logístico". O Estado normal, expressão criada por Domingo Cavallo, é definido por Cervo como aquele cuja conduta dá-se com três parâmetros: “como Estado 'subserviente' submete-se às coerções do centro hegemônico do capitalismo; como Estado ‘destrutivo', dissolve e aliena o núcleo central robusto da economia nacional e transfere renda ao exterior; como Estado 'regressivo' reserva para a nação funções da infância social.”41 O Estado logístico seria aquele que empreende uma inserção internacional madura, possibilitando aos setores nacionais operarem de maneira competitiva no exterior.

O Estado normal por excelência seria a Argentina de Menem. O Estado logístico foi implantado à mesma época no Chile. Ao Brasil restou uma “indefinição oriunda da coexistência paradigmática da política exterior (...) desde 1990”, levando “à agonia do Estado desenvolvimentista, à emergência do Estado normal e ao ensaio de Estado logístico" ${ }^{42}$ A atuação multilateral brasileira é resultado dessa confusão de paradigmas, que tem como acabamento um discurso diplomático idealista de inspiração kantiana, em um mundo guiado pelo realismo das grandes potências.

Raúl Bernal-Meza ${ }^{43}$ descreve e analisa a política externa brasileira dos anos 90, identificando especificidades dos diversos governos no período, assim como continuidades.

No plano das especificidades, o autor considera que o governo Collor, marcado pela modernização e adesão ao ideário neoliberal, teve como prioridades na agenda externa a aproximação dos Estados Unidos e o abandono do discurso terceiromundista. O governo Itamar Franco esteve marcado pela incorporação dos novos temas da agenda internacional à política externa e pelo ativismo no plano multilateral, que teria na busca de um assento permanente no Conselho de Segurança da ONU e na tentativa de construção da ALCSA algumas de suas manifestações mais importantes. Caracterizou-se também, no plano bilateral, pela 
construção de parcerias estratégicas. Os dois mandatos de Fernando Henrique Cardoso, enfim, são caracterizados pelo aprofundamento de posicionamentos das gestões presidenciais anteriores, “com especial atenção à gestão multilateral, com um marcado ativismo presidencial”"44, mais pragmático e de menor perfil político.

É no âmbito das continuidades que a interpretação de Bernal-Meza diferencia-se da de Cervo, entre outras. O autor identifica na formulação e reformulação da política externa brasileira, mesmo dos últimos anos, a permanência de conceitos-chave como o par desenvolvimento-autonomia. A exemplo de Hirst e Pinheiro, entende que existe um aspecto de continuidade essencial, que é a adaptação das estratégias de inserção internacional sem alterar-se o que há de mais importante na opção de inserção.

Esse aspecto é bastante evidente, segundo o autor, nas relações que o Brasil entretém com seus parceiros do Mercosul, notadamente com a Argentina. Entende que no plano do multilateralismo regional é notória a inspiração realista tanto dos policy makers quanto em seus intérpretes brasileiros. Nesse sentido, o Mercosul foi visto como "uma instância negociadora frente ao eventual estabelecimento de uma área hemisférica de livre comércio [Alca], e no âmbito político, o bloco permitiria dotar o Brasil de uma base maior de apoio para sua estratégia de alcançar reconhecimento como 'potência regional', em virtude da liderança que exerceria no interior do bloco e, por meio deste, no Cone Sul.” ${ }^{4}$ Portanto, a atuação da diplomacia brasileira nas negociações do Mercosul é substancialmente realpolitik; para os brasileiros a dimensão competitiva teria sempre prevalecido sobre a cooperativa.

\section{Considerações finais}

Viu-se que, de maneira geral, tem surgido, no Brasil e internacionalmente, uma farta literatura sobre e os organismos internacionais, regimes, e o multilateralismo de maneira geral, etc., o que parece atestar que multilateralism matters $^{46}$, e que o mundo não será menos multilateral amanhã.

O presente texto focalizou a relativamente pouco numerosa bibliografia brasileira que busca realizar um balanço da atuação multilateral brasileira. Nesse conjunto de trabalhos foi possível observar que alguns deles têm caráter mais descritivo e outros são mais analíticos. Também pôde-se ver que alguns estudos têm como objeto a política externa brasileira propriamente dita e outros o discurso diplomático, que explicita a visão que o Itamaraty tem sobre sua prática e das relações internacionais.

Mas o levantamento, ainda que com todos os seus limites explicitados, permite-nos também destacar temas que provavelmente devem ser revisitados, por vários motivos, entre os quais, talvez o mais relevante, o acesso que se tem a novas fontes. A política externa do governo Castello Branco, aparece como 
destaque. Malgrado a visão preponderante de que, em abril de 1964, a Política Externa Independente tenha sido abandonada pelos militares, vários sinais há de que o argumento não pode ser generalizado.

Nesse sentido, a primeira Unctad - que se desenrolava em Genebra no momento em que os militares assumem o poder e, para cuja realização, o Brasil contribuíra ativamente - é reveladora. Sabe-se atualmente que não houve modificação de instruções do que deveria ser defendido na reunião. E pode-se ir além para afirmar que a diplomacia econômica não só não foi rompida em abril de 1964, como aprofundada pelo governo Castelo Branco. ${ }^{47}$

Finalmente, viu-se como os paradigmas prestígio/desenvolvimento são tidos como orientadores da política multilateral brasileira. O prestígio teria norteado a ação externa do Brasil até os anos 30 . O desenvolvimento marcaria todo o período posterior. A relação entre tais paradigmas é vista praticamente de mútua exclusão.

Como referência empírica desses paradigmas tem-se utilizado a atuação brasileira na Liga das Nações e na ONU. A participação do Brasil na Liga das Nações é tida como exercício de diplomacia ornamental por excelência porque considera-se que as ações do governo brasileiro estiveram direta e unicamente ligadas ao prestígio que lhe trazia sua presença no Conselho. O Brasil se retiraria da Liga em 1926 ao ver que sua reivindicação a um assento permanente no Conselho não seria atendida. Além disso, o Brasil pouco tinha a ver com os problemas europeus que monopolizavam as atenções da Liga. ${ }^{48}$ No momento da fundação da ONU a instrumentalidade já prevaleceria na condução política externa brasileira. O Brasil teria aí uma ação constante, exercendo um papel bastante ativo na inserção da ideologia do desenvolvimento.

Parece, entretanto, que a inserção multilateral do Brasil chega aos anos 90 marcada por uma tal complexidade que não seria mais possível separar, em nenhum fórum multilateral, a dimensão instrumental daquela que seria, aos olhos de alguns, meramente ornamental: a busca de recursos para o desenvolvimento passaria necessariamente pela obtenção de posições de liderança. O esquema prestígio versus desenvolvimento provavelmente não se prestaria para explicar a complexidade das interações multilaterais do Brasil. ${ }^{49}$

Novembro de 2002

\section{Notas}

1 Cf. RUGGIE, John G. Multilateralism: the Anatomy of an Institution. In: RUGGIE, John. Multilateralism Matters. New York: Columbia University Press, 1993, p.4-11, principalmente.

2 O sistema de segurança coletiva previsto pela Carta da ONU nunca foi aplicado. Segundo seu Capítulo VII, a segurança coletiva repousaria sob a responsabilidade dos membros permanentes do Conselho de Segurança, a quem “todos os Membros das Nações Unidas (...) se comprometem 
a proporcionar (...), a seu pedido e de conformidade com o acordo ou acordos especiais, forças armadas (...). O acordo ou acordos serão negociados o mais cedo possível (...).” (Artigo, 43, 1) A paralisia do Conselho, em conseqüência dos vetos de seus membros permanentes, produziu inovações, como a transferência à Assembléia Geral da atribuição de manter a paz e a segurança internacionais, quando o Conselho estivesse paralisado , conforme a Resolução Acheson, de 1950 (Uniting for Peace Resolution). Com base nessa resolução, criou-se em 1956, a Força Internacional de Emergência das Nações Unidas (FENU I), que atuou durante dez anos da Península do Sinai. As operações de paz estão também amparadas no Artigo 40, do Capítulo VII da Carta, que prevê que o Conselho de Segurança, antes de recorrer a medidas de enforcement, poderá adotar medidas provisórias para prevenir o agravamento do conflito.

A partir dos conceitos sugeridos por Ruggie, a autora intenta refletir sobre os motivos da diminuição da relevância da OEA em BREDA DOS SANTOS, Norma. Cinqüenta anos de OEA: o que comemorar, Revista brasileira de política Internacional, ano 41, n. 2, 1998, p. 159-164.

4 ALVARES, José E. Multilateralism and its Discontents. European Journal of International Law, v. 11, n. 2, 2000, p. 3.

5 SLAUGHTER, Anne-Marie. The Real New World Order. Foreign Affairs, v. 76, n. 5, set./out. 1997, p. 194.

$6 \quad$ Para detalhes que reforçam os argumentos dos críticos ver Alvares, p. 395.

7 Tullo VIGEVANI. Ciclos longos e cenários contemporâneos da sociedade internacional. Revista Lua Nova, n. 46, 1999, p. 41, pondera ainda que “[é] importante ressaltar que a liderança vincula-se à capacidade, como observado por Ikenberry (1997), de projetar um formato de idéias políticas ou princípios e valores que tenham conexão com aqueles compartilhados por um razoável número de Estados. O campo dos valores sempre foi importante, mas ganha maior destaque no fim do século XX. Quando a hegemonia busca afirmar-se pela manifestação explícita de excesso de poder, corre o risco de sofrer erosão. Provavelmente esta seja uma explicação plausível para as dificuldades enfrentadas pelos Estados Unidos no equacionamento da crise do Iraque, que perduraram ao longo de toda a década dos noventa.” E que ainda perduram. Sobre a construção do consenso e da legitimidade durante a vigência da bipolaridade Leste/Oeste e na atualidade, também consultar a importante reflexão de FONSECA, Gelson. A legitimidade e outras questões internacionais, Rio de Janeiro: Paz e Terra, 1998, p. 137-248.

8 Carta Internacional, publicada desde março de 1993, é um informativo mensal do Núcleo de Pesquisa em Relações Internacionais (NUPRI) da USP. Panorama da Conjuntura Internacional é publicado bimensalmente pelo Grupo de Análise de Conjuntura Internacional (GACINT), também da USP. RelNet é uma iniciativa conjunta do Departamento de Relações Internacionais da Universidade de Brasília (REL-UnB) e da Fundação Alexandre de Gusmão (FUNAG), vinculada ao Ministério das Relações Exteriores (http://www.relnet.com.br).

Sobre a Revista Brasileira de Política Internacional, ver especialmente ROCHA, Antônio Jorge R. da. O tratamento de temas multilaterais pela RBPI: 1958-1998. Revista Brasileira de Política Internacional, Especial 40 Anos, 1998, p. 121-132.

10 Poucos trabalhos não se enquadram no âmbito de publicações proposto. Ver a seguir: Cançado Tindade, Selcher e Mello e Silva.

11 Tanto com relação à produção mais tradicional quanto à mais recente, não foi aqui considerada uma grande quantidade de material bibliográfico que trata da participação do Brasil em organizações, órgãos e conferências técnicas ou bastante específicas. Para o leitor ter uma idéia desse universo: conferências sobre produtos de base, sobre migrações, refugiados, população, questões sanitárias, transferência de tecnologia, propriedade intelectual, comunicações, etc.

12 O historiador francês Fernand Braudel classifica os tempos históricos em: tempo longo, que trata das mudanças estruturais que acontecem ao ritmo dos séculos; o tempo médio, que trata de mudanças conjunturais, que acontecem em intervalos de décadas dentro do quadro estrutural, e 
o tempo curto ou história imediata, que é contemporânea ao historiador. Ver, por exemplo, BRAUDEL, Fernand. Une leçon d'histoire. Paris: Arthaud, 1990.

CANÇADO TRINDADE, Antônio Augusto. Posições internacionais do Brasil no plano multilateral. Revista Brasileira de Estudos Políticos, n. 52, jan. 1981, p. 147-216.

Ibid., p. 148.

15 A exemplo da citação que o autor faz de um discurso do Ministro das Relações Exteriores (1968), Magalhães Pinto. Neste, o então ministro afirmava que o Gatt era uma "instituição de propósito limitado a realizações que beneficiam muito mais os países que já detêm a maior parcela de comércio internacional do que aqueles que vêem ano após ano decrescer sua pequena participação nas trocas mundiais”. Ibid. p. 184.

Ibid., p. 211

17 BUENO, Clodoaldo. A política multilateral brasileira. In: CERVO, Amado L. (org.). O desafio internacional. Brasília: Editora da UnB, 1994, p. 9-58.

18 Ibid., p. 132.

19 ALMEIDA, Paulo Roberto. A democratização da sociedade internacional e o Brasil: ensaio sobre uma mutação histórica de longo prazo (1815-1997). Revista Brasileira de Política Internacional, ano 40, n. 2, 1997, p. 76-105

20 Ibid., p. 76.

21 LAFER, Celso. Uma interpretação do sistema das relações internacionais do Brasil. Revista Brasileira de Política Internacional, set./dez. 1967, p. 81-100.

22 Ibid., p. 81.

23 Em um sistema político internacional, considera-se que existe balanço de poder quando o padrão de interações entre os Estados que o compõem visa a limitar a busca da hegemonia de um de seus componentes e a conseqüente quebra do equilíbrio geral. Foi com a finalidade principal de substituir o sistema de balança de poder pelo da segurança coletiva que a Liga das Nações foi criada após a Primeira Guerra Mundial, pois pregava o internacionalismo wilsoniano, principalmente, ser aquele sistema o principal responsável pelas multiplicações de conflitos bélicos no mundo.

24 Rubens Ricupero dá uma interpretação bem próxima à de Lafer em seu trabalho sobre a vida do Barão do Rio Branco. Ver RICUPERO. Rubens. José Maria da Silva Paranhos, Barão do Rio Branco: uma biografia fotográfica, 1984-1995. Organização iconografia e legendas de José Hermes Pereira de Araújo. Brasília/Rio de Janeiro: Funag , 1995.

25 Leia-se aqui, implicitamente, as únicas razões reais para que o Brasil participe da Liga das Nações e a desenvoltura com que dela se afasta, em 1926. Não tendo interesses a defender na Liga, além do prestígio (caráter ornamental) que os mandatos seguidos no Conselho traziam-lhe, o Brasil pôde deixar a Liga sem grandes prejuízos.

LAFER, Celso. Uma interpretação ..., op. cit., p. 91.

MELLO E SILVA, Alexandra de. Idéias e política externa: a atuação brasileira na Liga das Nações e na ONU, Revista Brasileira de Política Internacional, 1998, n. 2, p. 148. Ibid., p. 139

Ibid., p. 154.

SELCHER, Wayne A. Brazil's Multilateral Relations: between First and Third Worlds. Boulder: Westview Press, 1978.

Vide também SELCHER, Wayne. As linhas fluidas da ação multilateral do Brasil. A defesa nacional, n. 679, set./out. 1978, p. 137-148. 
Cf. http://www.usp.br/relint/

MIYAMOTO, Shiguenoli. O Brasil e as negociações multilaterais. Revista Brasileira de Política Internacional, ano 43, n. 1, 2000, 119-137.

Ibid., p. 122.

Ibid., p. 135.

CERVO, Amado. Relações internacionais do Brasil: um balanço da era Cardoso. Revista Brasileira de Política Internacional, ano 43, n. 1, 2002, p. 5-35.

Ibid., p. 6.

Ibid., p. 7.

BERNAL-MEZA A política exterior do Brasil: 1990-2002. Revista Brasileira de Política Internacional, ano 45, n. 1, 2002, p. 36-71.

Ibid., p. 61.

Ibid., p. 44.

Título do referido livro organizado por John Ruggie.

Marcílio Marques Moreira era então diplomata e acompanhava assuntos econômicos no Itamaraty. Afirma que "houve uma comissão [brasileira] muito dinâmica de preparação [da primeira reunião da Unctad]. (...) [H]avia cinco grupos de trabalho - é por isso que eu digo que o problema não era só o Gatt; era também o Fundo Monetário Internacional e o Banco Mundial. (...) O que essa preparação mostra é que a política externa independente tinha afinal adquirido uma dimensão econômica. Até então, ela, que procurava se aproveitar de uma brecha possível na rivalidade Leste-Oeste entre países desenvolvidos, não tinha apresentado uma vertente econômica consistente. A orientação era muito marcadamente política (...).” Afirma ainda que a orientação traçada pela referida comissão foi seguida, "mesmo depois da Unctad”. E acrescenta: "Nossa posição sempre foi reivindicatória, nunca deixou de ser. O que mudou foi a retórica.” (Moreira, p. 95-96 e 115)

A historiografia brasileira sobre o tema insiste sobre a idéia de “fiasco" brasileiro em Genebra, produto da misperception das elites dirigentes brasileiras, somada à necessidade do autocrático governo Bernardes de utilizar a política externa para fins de legitimação política doméstica. A passagem do Brasil pela Liga das Nações não pode, porém, ser compreendida realmente sem uma perspectiva que busque inseri-la em um contexto mais amplo, que teria basicamente a ver com o relacionamento entre as principais potências européias e suas políticas em assuntos que diziam respeito à Liga. A tese de doutorado da autora teve como objetivo fazer essa análise mais ampla, utilizando, além da documentação brasileira pertinente, fontes britânicas e francesas, particularmente. Cf. BREDA DOS SANTOS, Norma. Le Brésil et la Société des Nations, 1920-1926. Tese de doutorado. Université de Genève/Institut Universitaire de Hautes Etudes Internationales, 1996.

Sobre a candidatura brasileira ao assento permanente no Conselho de Segurança, vide HERTZ, Mônica. O Brasil e a reforma da ONU. Revista Lua nova, n. 46, 1999, p. 77-99.

\section{Bibliografia}

ALMEIDA, Paulo Roberto. A democratização da sociedade internacional e o Brasil: ensaio sobre uma mutação histórica de longo prazo (1815-1997). Revista Brasileira de Política Internacional, ano 40, n. 2, 1997, p. 76-105.

ALVARES, José E. Multilateralism and its Discontents. European Journal of International Law, v. 11, n. 2, 2000, p. 393-411.

BERNAL-MEZA A política exterior do Brasil: 1990-2002. Revista Brasileira de Política Internacional, ano 45, n. 1, 2002, p. 36-71. 
BREDA DOS SANTOS, Norma. Cinqüenta anos de OEA: o que comemorar. Revista Brasileira de Política Internacional, ano 41, n. 2, 1998, p. 159-164.

BREDA DOS SANTOS, Norma. La projection multilatérale du Brésil. In: Le Brésil, l’Europe et les équilibres internationaux, XVIe-XXe siècles. Paris: Presses Universitaires de France/ Centre d'études sur le Brésil-Sorbonne, 1999, p. 311-320.

BUENO, Clodoaldo. A política multilateral brasileira. In: CERVO, Amado L. (org.). O desafio internacional. Brasília: Editora da UnB, 1994, p. 9-58.

CANÇADO TRINDADE, Antônio Augusto. Aspectos institucionais das relações internacionais na América Latina. Revista Brasileira de Estudos Políticos e Estratégia, n. 52, jan. 1981, p. 2852.

CANÇADO TRINDADE, Antônio Augusto. Posições internacionais do Brasil no plano multilateral. Revista Brasileira de Estudos Políticos, n. 52, janeiro 1981, p. 147-216.

CERVO, Amado. Relações internacionais do Brasil: um balanço da era Cardoso. Revista Brasileira de Política Internacional, ano 45, n.1, 2002, p. 5-35.

FONSECA, Gelson. A legitimidade e outras questões internacionais, Rio de Janeiro: Paz e Terra, 1998.

HERTZ, Mônica. O Brasil e a reforma da ONU. Revista Lua nova, n. 46, 1999, p. 77-99.

HIRST, Mônica \& PINHEIRO, Letícia. A política externa do Brasil em dois tempos, Revista Brasileira de Política Internacional, ano 38, n. 1,1995, p. 5-23.

LAFER, Celso. Uma interpretação do sistema das relações internacionais do Brasil. Revista Brasileira de Política Internacional, set./dez. 1967, p. 81-100.

MELLO E SILVA, Alexandra de. Idéias e política externa: a atuação brasileira na Liga das Nações e na ONU, Revista Brasileira de Política Internacional, ano 41, n. 2, 1998 (a), p. 139-158.

MELLO E SILVA, Alexandra de. O Brasil e o Conselho de Segurança da ONU. Carta Internacional, ano VI, n. 68, out.1998 (b).

MIYAMOTO, Shiguenoli. O Brasil e as negociações multilaterais. Revista Brasileira de Política Internacional, ano 43, n. 1, 2000, p. 119-137.

MOREIRA, Marcílio Marques. Diplomacia, política e finanças. De JK a Collor: 40 anos de história por um de seus protagonistas. Entrevista à Fundação Getúlio Vargas. Rio de Janeiro: Objetiva, 2001.

RICUPERO, Rubens. José Maria da Silva Paranhos, Barão do Rio Branco: uma biografia fotográfica, 1984-1995. Organização, iconografia e legendas de José Hermes Pereira de Araújo. Brasília/Rio de Janeiro: Funag, 1995.

RUGGIE, John (org.) Multilateralism Matters. New York: Columbia University Press, 1993.

SELCHER, Wayne A. Brazil's Multilateral Relations: between First and Third Worlds. Boulder: Westview Press, 1978.

SELCHER, Wayne A. As linhas fluidas da ação multilateral do Brasil. A defesa nacional, n. 679, set./out. 1978, p. 137-148.

SLAUGHTER, Anne-Marie. The Real New World Order. Foreign Affairs, v. 76, n. 5, set./out. 1997, p. 183-197.

VIGEVANI, Tullo. Ciclos longos e cenários contemporâneos da sociedade internacional. Revista Lua Nova, n. 46, 1999.

\section{Resumo}

A política externa brasileira é abordada aqui em seu aspecto multilateral, por meio de uma revisão bibliográfica tendo como fonte principal os periódicos brasileiros especializados em relações internacionais. Procura-se traçar um 
panorama dos estudos sobre a atuação multilateral do Brasil em dois tempos históricos: o primeiro referente a um tempo mais longo, em busca dos aspectos conjunturais, e o segundo tratando da história do tempo presente, especificamente as últimas três décadas.

\section{Abstract}

Brazilian Foreign Policy is treated here in its multilateral side towards a bibliographical review that has as main source Brazilian periodicals specialized in international relations. It aims to trace a panorama of the studies about Brazil's multilateral action in two historical times: the first refers to a longer period, that looks for conjectural aspects, and the second is related to the present time history, specifically the three last decades.

Palavras-chave: Política externa brasileira; Multilateralismo; Produção bibliográfica. Key words: Brazilian Foreign Policy; Multilateralism; Bibliographical production. 